encuentran sumergidas en los capitulos anteriores. Las relaciones entre los trabajadores son utilizadas por diversas construcciones teóricas sobre la categoriatrabajo y para comprensión de sus interacciones. El campo de la individualidad, de la subjetividad, han sido foco de interés de la sociología de la educación y de la salud, especificamente la de salud mental em el trabajo. El espacio de la subjetividad, hace um puente para otros territorios donde la interacción concretiza el movimiento de espacios distintos. La dimensión individual y colectiva de los fenómenos encontrados em los espacios de trabajo, no pueden der comprendidas uma sin la outra. Los datos recogidos en el elementos para la comprensíon de estas nuevas dimensiones.

\title{
COTIDIANO DO TRABALHO DA ENFERMAGEM EM UTI: PRAZER OU SOFRIMENTO?
}

Autora: Josiane de Jesus Martins Orientadora: Eliana Marilia Faria

RESUMO: Este estudo teve como objetivo identificar os fatores geradores de prazer e sofrimento no cotidiano do trabalho da enfermagem. Foi realizado em uma Unidade de Terapia Intensiva (UTI) de um hospital de ensino pertencente à Universidade Federal de Santa Catarina. Trata-se de uma pesquisa da área humano-social do tipo exploratório, descritivo e analítico, com abordagem qualitativa. Para a construção do suporte teórico busquei contribuições de autores que tratam do tema referente à psicopatologia do trabalho e o processo de trabalho em saúde. Os dados foram coletados através da aplicação de um questionário semi-estruturado supervisionado com 24 trabalhadores de enfermagem da UTI, seguido da apresentação dos dados para validação e a formação de um grupo focal. Para a análise dos dados foi utilizada a análise de conteúdo. Os resultados foram apresentados através de dados sócio-demográficos e categorias centrais como: as manifestações do prazer no processo de trabalho da enfermagem em que se sobressai a recuperação do sujeito hospitalizado, a realização das técnicas (cuidados) de enfermagem, o reconhecimento pelo trabalho realizado e a harmonia no ambiente de trabalho. As manifestações do sofrimento e do desprazer no trabalho emergem das seguintes categorias: relacionamento interpessoal conflituoso, morte e a dor física do sujeito hospitalizado, sofrimento dos familiares, falta ou escassez de materiais e a mecanização de trabalho. Outra categoria analisada refere-se ao uso de tecnologias e o impacto destas na organização do trabalho. Apresento também, dados referentes às oficinas realizadas para discutir questões pertinentes ao relacionamento interpessoal conflituoso, apontado pelos trabalhadores como o fator de maior significado na gênese de sofrimento no trabalho. Finalizando a análise dos dados, aponto as sugestões fornecidas pelos trabalhadores em obter a realização de um trabalho prazeroso e as percepções dos mesmos em relação ao seu trabalho. O conhecimento dos fatores que propiciam prazer, desprazer e sofrimento no trabalho, abre novas possibilidades de mudanças para o trabalho da enfermagem, contribuindo assim, para a realização de um processo participativo, inovador, impregnado de ética e mais humanizado.

\section{COMPREENDER O PROCESSO DE TRABALHO DA ENFERMAGEM: UMA NECESSIDADE PARAA PROFISSÃO}

Autora: Maritê Inez Argenta Orientadora: Denise Elvira Pires de Pires

\footnotetext{
RESUMO: A finalidade deste estudo foi fazer uma reflexão com os trabalhadores de enfermagem (enfermeiros, técnicos e auxiliares de enfermagem) de uma instituição hospitalar pertencente à rede pública do Estado de Santa Catarina, de uma unidade cirúrgica, tendo como objetivo refletir sobre o seu processo de trabalho. Analisa como esse processo é percebido pelos trabalhadores de enfermagem o que lhes proporciona sofrimento e prazer no exercício do mesmo. Trata-se de um estudo de caso, analisado segundo critérios da pesquisa qualitativa. Para coleta de dados foram utilizadas entrevistas semi-estruturadas individuais, discussões em grupo, sob a forma de oficinas; observação de campo e estudo documental. Participaram das entrevistas 14 (quatorze) profissionais de enfermagem da unidade estudada e, em cada grupo de discussão, participaram em média 8 (oito) trabalhadores. Os dados foram categorizados de acordo com a opinião de quem o realiza e sistematizados destacando os elementos que compõem o processo de trabalho e opiniões sobre o sofrimento e prazer no trabalho de enfermagem. este estudo constatou que apesar das teorizações já existentes sobre o processo de trabalho no cotidiano, os trabalhadores de enfermagem têm dificuldades de identificar a finalidade e o objeto sobre o qual atua e, esta dificuldade influencia a compreensão da enfermagem sobre a sua profissão. Os profissionais da enfermagem não se questionam sobre: as caracteristicas especiais do objeto de trabalho e a especificidade do seu trabalho, as quais o diferenciam no contexto do trabalho em saúde. que instrumentos são necessários para o exercício do trabalho em enfermagem e que características deve ter a força de trabalho para realizar esse tipo de atividade. Que conhecimentos específicos são
} 
dominados pela profissão no conjunto das profissões em saúde. Conclui-se que o processo de trabalho da enfermagem gera sofrimento nos trabalhadores, principalmente pelas condições de trabalho adversas e pela falta de reconhecimento social, mas, também pode ser uma fonte de prazer aos trabalhadores. Este trabalho complexo e especifico, inclui a possibilidade dos trabalhadores imprimirem a sua marca, a sua criatividade e, é possivel a enfermagem realizar um trabalho mais humano e mais valorizado. Apesar das condições adversas, existe uma identidade dos trabalhadores com a profissão, além de uma simples relação de emprego para sobrevivência. O domínio de um conhecimento especial une, e dá identidade ao grupo, apesar dos conflitos.

\section{MANIFESTAÇÃO DO PODER SEGUNDO A PERCEPÇÃO DE ENFRMEIROS QUE ATUAM EM UMA INSTITUIÇÃO HOSPITALAR PÚBLICA}

Autora: Valéria Bertonha Machado Orientadora: Paulina Kurcgant

RESUMO: Para compreender como o poder, enquanto fenômeno que envolve as relações de trabalho é experienciado e percebido pelos enfermeiros que atuam em uma instituição hospitalar pública e de ensino, foi realizado este estudo qualitativo no referencial fenomenológico, segundo a modalidade da <estrutura do fenômeno situado>. A região de inquérito, constituiu a vivência dos enfermeiros que atuam em um hospital público de ensino pertencente a uma Universidade. Os sujeitos participantes do estudo foram nove enfermeiros que vivenciam, no seu cotidiano de trabalho, as relações de poder. A obtenção dos depoimentos foi norteada pela questão < como você percebe as manifestações de poder no seu dia a dia de trabalho? > . Através da análise ideográfica dos 9 depoimentos foram resgatados os seguintes temas: < As manifestações de poder com a equipe de Enfermagem>; < As manifestações de poder no contexto organizacional >; < As manifestações de poder com os pacientes >; < As manifestações de poder com a equipe Médica>. A análise nomotética possibilitou a compreensão da estrutura geral do fenômeno, pelas proposições que emergiram da análise das convergências, divergências e idiossincrasias das unidades de significado interpretadas. Essas proposições desvelaram que a estrutura hierárquica da instituição pública bem como o conhecimento desempenham papel importante nas relações de poder com a equipe de Enfermagem. Alguns enfermeiros consideram que o comando, a cobrança e o controle são instrumentos adotados pelo enfermeiro para exercer poder na relação com a sua equipe. Outros consideram que a melhor maneira para o exercício do poder é fazê-lo de forma participativa. Outros ainda consideram que o autoritarismo, os relatórios de atividades e a avaliação de desempenho quando utilizados por profissionais despreparados, são uma forma negativa de exercício do poder. Ao Departamento de Enfermagem é atribuído poder junto ao contexto organizacional pela seriedade e qualidade do trabalho realizado. Nas relações de poder pessoal de Enfermagem/pacientes é atrịbuído, à equipe de Enfermagem, maior poder. Quanto às relações de poder com a equipe Médica, alguns enfermeiros atribuem, à figura do médico, maior poder e outro considera que as relações entre equipe Médica e de Enfermagem ocorrem de forma igualitária. 